\title{
РАНЖИРОВАНИЕ АДМИНИСТРАТИВНЫХ РАЙОНОВ ХАРЬКОВСКОГО РЕГИОНА ПО УРОВНЮ ЭКОЛОГИЧЕСКОГО РИСКА
}

\author{
(C) Ю. В. Буц, Е. В. Крайнюк
}

Представлено ранжирование территории Харьковской области по возможному экологическому риску от возникновения чрезвычайных ситуаџий на объектах повыленной опасности. Создана карта уровня экологической опасности в районах области. Оченена плотность размещения потенциальных источников чрезвычайных ситуаций для районов области, дающая право с достоверной долей условности говорить о степени техногенной опасности территории исследованных районов

Ключевые слова: экологический риск, потенцииально опасный объект, объект повыщенной опасности, чрезвычайная ситуация

Ranging of territory of the Kharkov region with a possible ecological risk from the origin of emergency situations on the objects of enhanced danger is presented. The map of ecological threat level is created in the districts of area. The closeness of placing of potential sources of emergency situations is appraised for all region districts which gives a right with the reliable fate of convention to talk about the measure of technogenic danger of territory of investigational districts

Keywords: ecological risk, potentially dangerous object, object of enhanced danger, emergency situation

\section{1. Введение}

Украина по насыщенности территории промышленными объектами превышает развитые европейские государства. Значительную часть из них составляют потенциально опасные предприятия (ПОП), связанные с производством, переработкой и хранением сильнодействующих ядовитых, взрывоопасных и пожароопасных веществ. На сегодняшний день Государственный реестр потенциально опасных объектов содержит подробные сведения о более, чем 23 тыс. объектах, в число которых входят промышленные предприятия, шахты, карьеры, магистральные газо-, нефте- и продуктопроводы, гидротехнические сооружения, узловые железнодорожные станции, мосты, тоннели, накопители и полигоны промышленных отходов, места хранения опасных веществ и др. \section{проблемы \\ 2. Анализ литературных данных и постановка \\ Наибольшее количество потенциально опасных} объектов расположено на территории Донецкой, Днепропетровской, Запорожской, Харьковской и Львовской областей. В основном, это - пожароопасные (41\%), взрывоопасные (37\%), химически опасные (7,9\%), радиационно-опасные $(2,1 \%)$, гидродинамические опасные $(1,85 \%)$ и биологически опасные $(1,8 \%)$ объекты. По данным Государственной службы Украины по чрезвычайным ситуациям по состоянию на 31 декабря 2013 года в государственный реестр объектов повышенной опасности внесено 9382 объектов [1]. В Харьковской области насчитывается 381 объект повышенной опасности [2]. Объект повышенной опасности (ОПО) - объект, на котором используется, изготовляется, перерабатывается, хранится или транспортируется одно или несколько опасных веществ или категорий веществ в количестве, которое равняется или превышает нормативно установленные пороговые массы, а также другие объекты такие, которые в соответствии с законом являются реальной угрозой возникновения чрезвычайной ситуации (ЧС) техногенного и природного характера [3].

Разные аспекты и отдельные подходы к исследованию вопроса экологического риска и безопасности от ОПО отражены в трудах отечественных ученых и специалистов, среди которых стоит отметить Барбашову Н. В. [4], Бегуна В. В. [5], Данилишина Б. М. [6, 7], Дорогунцова С. И. [8], Качинского А. Б. [9], Яцика А. В. [10] и других.

Риск возникновения ЧС техногенного и экологического характера в значительной мере определяется состоянием объектов повышенной опасности [11]. Кризис в экономике, который сопровождается увеличением части устарелых технологий и оборудования, снижением уровня модернизации, обновления производства, повышает риск техногенных катастроф. Высокая концентрация населения и промышленного производства оказывают негативное влияние на окружающую среду, а в отдельных регионах в связи с неравномерностью расселения населения и размещения промышленного производства на территории Украины такое влияние создавало очень напряженную экологическую ситуацию [12].

\section{3. Цель и задачи исследования}

Цель научной работы заключается в определении уровня экологического риска от возникновения ЧС на объектах повышенной опасности и ранжирование административных объектов с составлением картографического материала.

4. Исследование вероятности возникновения чрезвычайных ситуаций техногенного и экологического характера в Харьковском регионе

Существует прямая зависимость возникновения ЧС от концентрации опасных производств в регионах. Наивысший уровень возникновения ЧС техногенного характера фиксируется в Харьковской, Запорожской, Донецкой и Луганской областях, где он колеблется от 
11 до 16 случаев в год. Регионы с наибольшим количеством потенциально опасного производства совпадают с регионами наибольшего сосредоточения населения. В частности, в Харьковской, Запорожской, Донецкой, Луганской и Днепропетровской областях, где функционирует 38 \% объектов от общего их числа, проживает 32,9 \% населения.

Ситуацию усложняет несоблюдение правил техногенной безопасности. Так, наихудшее состояние сложилось в Волынской (на 50 \% выполнены мероприятия по техногенной безопасности), Запорожской (37\%), Львовской (46\%), Одесской (25\%), Тернопольской (45\%), Харьковской (49 \%) и Черновицкой (38 \%) областях. При этом всего 3,6 \% объектов повышенной опасности оборудованы системами раннего обнаружения ЧС и оповещения людей в случае их обнаружения. О целесообразности внедрения систем раннего обнаружения ЧС свидетельствует и международный опыт: аналогичные системы используются в Соединенных Штатов Америки, химически опасных объектах Германии и других стран Евросоюза [13-16].

Анализ динамики индивидуального риска гибели от ЧС на объекте повышенной опасности в Харьковской области свидетельствует о его существенных изменениях на протяжении 2000-2004 гг., после чего происходил его постепенный рост до уровня $1 \cdot 10^{-5}$ в 2009 г. За исключением 2000, 2003, 2009 и 2011 гг. уровень индивидуального риска гибели в области (рис. 1) был существенно ниже государственного [17].

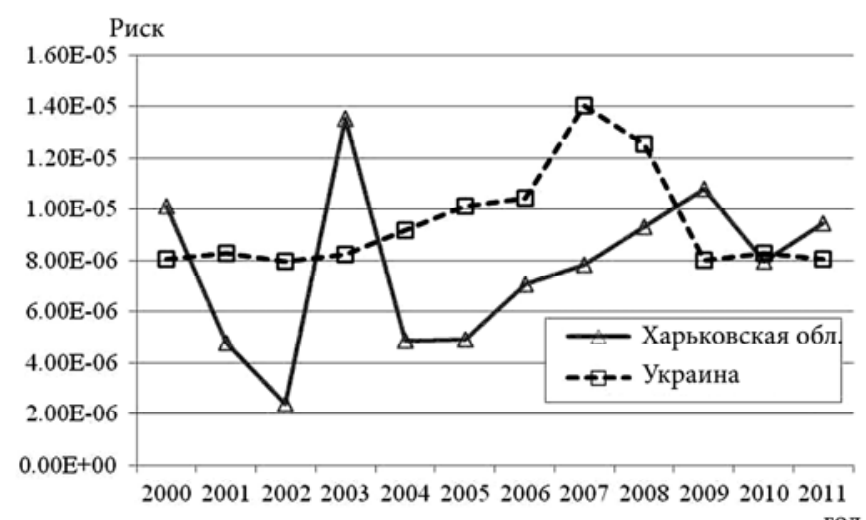

Рис. 1. Индивидуальный риск гибели в результате ЧС в Харьковской области

Из данных о вероятностях и рисках техногенных аварий и катастроф на объектах с исключительно высокой потенциальной опасностью следует, что расхождения уровней необходимых и приемлемых (в национальных и международных рамках) рисков, с одной стороны, и уровней реализованных рисков - из другой, достигают двух и больше по- рядков. В то же время известно, что повышение уровня защищенности объектов от аварий и катастроф на один порядок требует больших усилий в научно-технической сфере и существенных расходов - на уровне 10-20\% стоимости проекта.

Распределение потенциального риска и плотности населения в Харьковском регионе позволяет получить количественную оценку социального риска для населения. Избыточная плотность населения в отдельных районах области является одним из факторов, которые повышают материальный и социальный риск территории региона от стихийных бедствий и техногенных аварий. Нами создана карта ранжирования разноуровневых районов региона. Уровень риска от чрезвычайной ситуации отображает закономерности пространственной структуры потенциальных источников ЧС и позволяет повысить готовность исполнительной власти и уполномоченных служб к действиям при внезапном возникновении ЧС и к их предупреждению.

5. Анализ риска возникновения чрезвычайной ситуации экологического характера на основе размещения объектов повышенной опасности на территории Харьковской области

Проведем анализ риска возникновения возможной ЧС экологического характера на основе размещения объектов повышенной опасности на территории Харьковской области. Всего, согласно государственному реестру ОПО, на территории региона насчитывается 381 объект, на территории Украины - 9382 ОПО [2].

Риск возникновения экологически опасного события зависит от плотности размещения ОПО в регионе. Для всех районов области рассчитан коэффициент $\mathrm{f}$ (мера насыщенности территории опасными объектами), указывающий площадь, которая приходится на каждый ОПО (табл. 1). Мера насыщенности территории опасными объектами вычислена для точечных объектов на единицу площади $\left(\mathrm{k}^{2}\right)$. По мере насыщенности территории опасными производственными объектами с определенной долей вероятности можно судить и о достоверности возникновения ЧС техногенного характера. Чем больше насыщенность, тем больше вероятность возникновения ЧС.

На основе проанализированных показателей, нами было проведено ранжирование и группирование районов Харьковского региона по уровню экологического риска и составлена карта экологической опасности Харьковской области от ОПО (рис. 2). 
Таблица 1

Риск возникновения чрезвычайной ситуации в Харьковской области от объектов повышенной опасности

\begin{tabular}{|c|c|c|c|c|c|c|}
\hline Район & 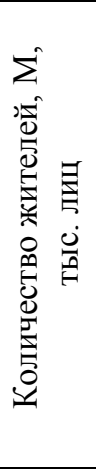 & 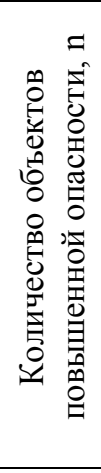 & 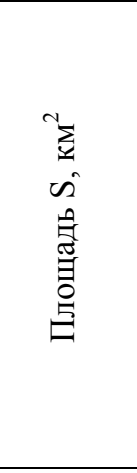 & 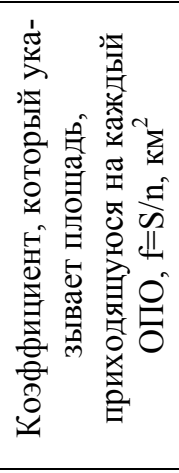 & 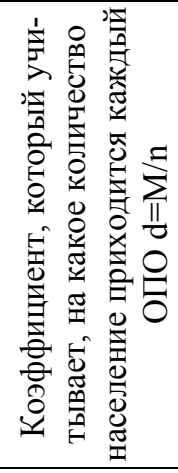 & 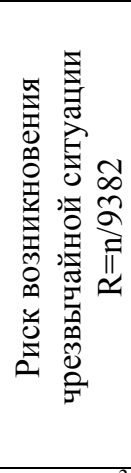 \\
\hline Балаклейский & 84,6 & 13 & 1986,5 & 152,8 & 6507 & $1,4 \cdot 10^{-3}$ \\
\hline Барвенковский & 24,7 & 3 & 1364,5 & 454,8 & 8233 & $3,2 \cdot 10^{-4}$ \\
\hline Близнюковский & 20,7 & 3 & 1380 & 460 & 6900 & $3,2 \cdot 10^{-4}$ \\
\hline Богодуховский & 40,4 & 14 & 1160,3 & 82,8 & 2885 & $1,5 \cdot 10^{-3}$ \\
\hline Боровский & 17,8 & 3 & 875,3 & 291,7 & 5933 & $3,2 \cdot 10^{-4}$ \\
\hline Валковский & 32,6 & 2 & 1010,5 & 505,2 & 16300 & $2,1 \cdot 10^{-4}$ \\
\hline Великобурлуцкий & 23,7 & 5 & 1220,8 & 244,1 & 4740 & $5,3 \cdot 10^{-4}$ \\
\hline Волчанский & 48,7 & 6 & 1888,6 & 314,7 & 8116 & $6,4 \cdot 10^{-4}$ \\
\hline Двуречанский & 18,8 & 4 & 1112,4 & 278,1 & 4700 & $4,3 \cdot 10^{-4}$ \\
\hline Дергачевский & 94,9 & 35 & 900,1 & 25,7 & 2711 & $3,7 \cdot 10^{-3}$ \\
\hline Зачепиловский & 16,1 & 3 & 794 & 264,6 & 5366 & $3,2 \cdot 10^{-4}$ \\
\hline Змиевской & 73 & 18 & 1364,7 & 75,8 & 4055 & $1,9 \cdot 10^{-3}$ \\
\hline Золочевский & 27,8 & 5 & 968,6 & 193,7 & 5560 & $5,3 \cdot 10^{-4}$ \\
\hline Изюмский & 18,7 & 20 & 1553,5 & 77,6 & 935 & $2,1 \cdot 10^{-3}$ \\
\hline Кегичевский & 21,8 & 3 & 782,5 & 260,8 & 7266 & $3,2 \cdot 10^{-4}$ \\
\hline Коломакский & 7,7 & 1 & 329,5 & 329,5 & 7700 & $1,0 \cdot 10^{-4}$ \\
\hline Красноградский & 45,8 & 14 & 985,1 & 70,3 & 3271 & $1,5 \cdot 10^{-3}$ \\
\hline Краснокутский & 29,3 & 5 & 1040,8 & 208,1 & 5860 & $5,3 \cdot 10^{-4}$ \\
\hline Купянский & 26 & 17 & 1280,3 & 75,3 & 1529 & $1,8 \cdot 10^{-3}$ \\
\hline Лозовский & 30,7 & 10 & 1403,5 & 140,3 & 3070 & $1,8 \cdot 10^{-3}$ \\
\hline Нововодолажский & 34,9 & 9 & 1182,7 & 131,4 & 3877 & $9,6 \cdot 10^{-4}$ \\
\hline Первомайский & 48,2 & 17 & 1194,5 & 70,2 & 2835 & $1,8 \cdot 10^{-3}$ \\
\hline Печенежский & 10,5 & 2 & 467,5 & 233,7 & 5250 & $2,0 \cdot 10^{-4}$ \\
\hline Сахновщинский & 22,5 & 7 & 1169,9 & 167,1 & 3214 & $7,5 \cdot 10^{-4}$ \\
\hline Харьковский & 183 & 124 & 1403,4 & 11,3 & 1475 & $1,2 \cdot 10^{-2}$ \\
\hline Чугуевский & 46,9 & 34 & 1148,6 & 33,7 & 1379 & $3,6 \cdot 10^{-3}$ \\
\hline Шевченковский & 21,2 & 4 & 977,4 & 244,3 & 5300 & $4,2 \cdot 10^{-4}$ \\
\hline Всего & 1071 & 381 & 30945,5 & 81,2 & 2811 & $4,0 \cdot 10^{-2}$ \\
\hline
\end{tabular}

6. Ранжирование территории Харьковской области по уровню экологического риска от возникновения чрезвычайных ситуаций на объектах повышенной опасности

По расчетам в первой группе оказались Харьковский, где на каждых 11,3 км² приходится 1 объект повышенной опасности. В Дергачевском и Чугуевском районе на каждые 25,7 и 33,7 км² (соответственно приходится по объекту повышенной опасности). Ко второй группе отнесены районы, где на каждых 70-83 км² размещен ОПО. Богодуховский, Змиевской, Изюмский, Красноградский, Купянский, Первомайский районы. Золочевский, Балаклейский, Лозовской, Нововодолажский, Сахновщинский районы составляют группу, в которых на каждые 130-200 км² размещен ОПО. Другие районы имеют наименьшую плотность размещения

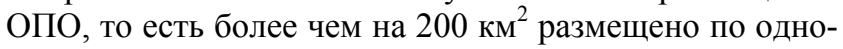
му объекту повышенной опасности. В среднем по ре- гиону на каждых 81,2 км² размещен объект повышенной опасности.

Для анализа экологической опасности также целесообразным является учет количества жителей в каждом районе. Для этого был рассчитанный коэффициент d (табл. 1). Наивысший коэффициент оказался для Изюмского района, где на каждые 935 человек приходится по одному ОПО. Высокие значения коэффициентов также для Харьковского, Чугуевского и Купянского районов, для которых по одному ОПО придется на 1379-1529 жителей. На карте эти регионы имеют наибольшую круговую диаграмму. От 2000 до 3000 тыс. человек на каждый ОПО приходится в Сахновщинском, Первомайском, Лозовском, Дергачевском и Богодуховском районах, которые отмечены диаграммами меньшего размера. Еще меньшего размера диаграммами на карте маркированы Боровский, Великобурлуцкий, Двуречанский, Зачепиловский, Змиевской, Золочевский, Красноградский, Нововодолажский, Сахнов- 
щинский районы, в которых на 3000-6000 жителей приходится по одному ОПО. Другие районы промаркированы наименьшей диаграммой, поскольку в них свыше 7000 человек приходится на каждый ОПО. В

целом в регионе на один объект повышенной опасности приходится 2811 жителей.

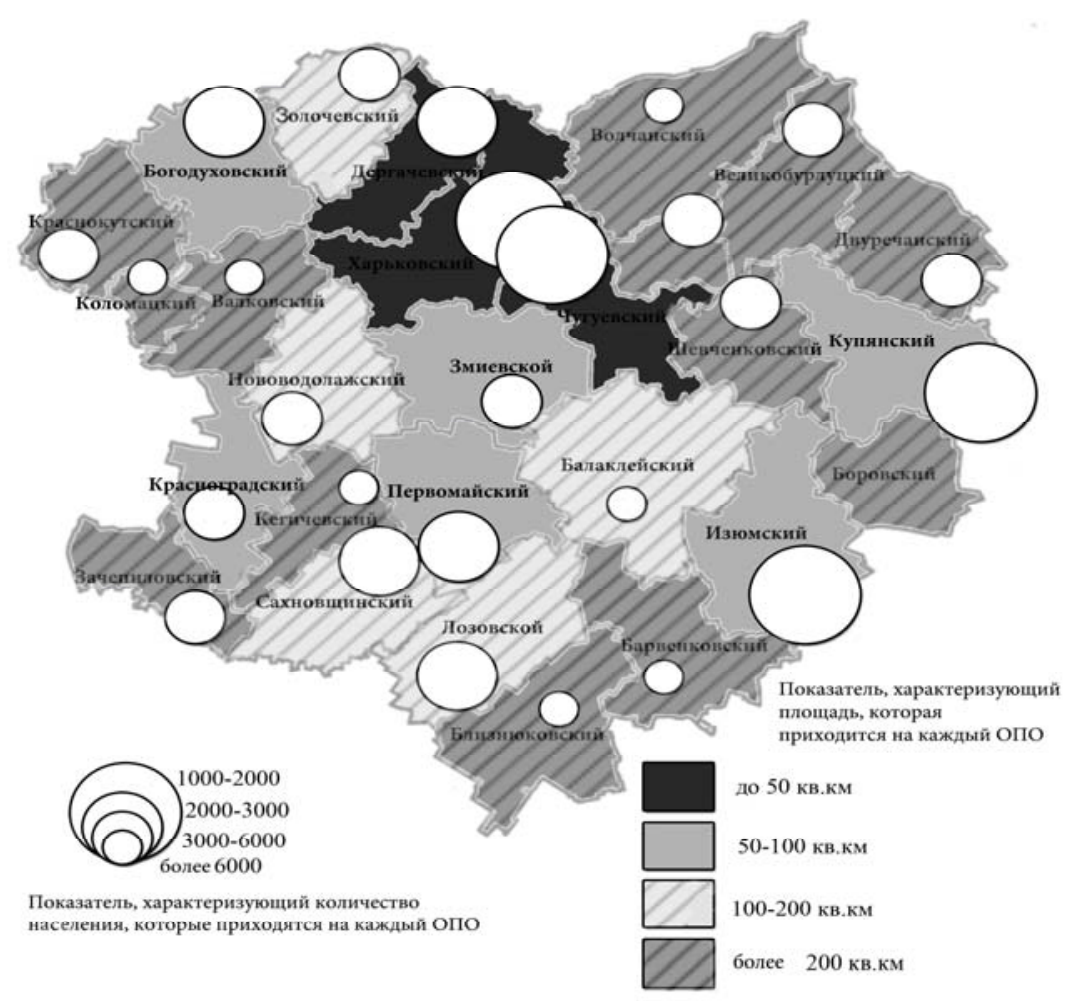

Рис. 2. Экологическая опасность Харьковской области

Риск возникновения ЧС на одном из рассмотренных объектов рассчитанный как отношение количества ОПО в районе к общему количеству аналогичных объектов на территории всей страны (табл. 1). Наивысший уровень риска в Харьковском районе $-1,2 \cdot 10^{-2}$, наименьший в Коломакском $-1,0 \cdot 10^{-4}$. В целом, по полученным расчетам достаточно высокий уровень риска возникновения техногенной ЧС в Харьковском регионе и составляет $4,0 \cdot 10^{-2}$.

\section{7. Выводы}

Проведенные исследования, направленные на определение уровня экологического риска, дали возможность ранжировать административные районы Харьковского региона по степени экологической опасности от ОПО.

Имеющиеся данные позволили нам оценить плотность размещения потенциальных источников техногенных ЧС для всех районов области, что дает право с достоверной долей условности говорить о мере техногенной опасности территории исследованных районов Харьковского региона.

Последующие изыскания в данном направлении следует сосредоточить на дифференциации ОПО по классам опасности и определения факторов, повышающих и снижающих риски возникновения чрезвычайных ситуаций от объектов повышенной опасности.

Литература

1. Національна доповідь про стан техногенної та природної безпеки України в 2013 році [Текст] / К: Вид-во МНС, 2013. -542 c.
2. Статистичний щорічник [Текст] / за ред. О. Г. Мамонтової. - Харків: ГУС Харківської обл., 2012. - 578 с.

3. Закон України «Про об'єкти підвищеної небезпеки» [Текст] / Відомості Верховної Ради України (ВВР), 2001, № 15 , ст. 73 .

4. Барбашова, Н. В. Екологічна безпека промислово розвиненого регіону: правовий аспект [Текст] / Н. В. Барбашова. - Донецька держ. академія управління. - Донецьк: ДонДАУ, 2002. -227 с.

5. Бєгун, В. В. Безпека життєдіяльності (забезпечення соціальної, техногенної та природної безпеки) [Текст]: навч. посіб. / В. В. Бєгун, І. М Науменко. - К.: Университет, 2004. - 328 с.

6. Данилишин, Б. М. Наукові основи прогнозування природно-техногенної (екологічної) безпеки [Текст] / Б. М. Данилишин, В. В. Ковтун, А. В. Степаненко. - К.: Лекс Дім, 2004. $-552 \mathrm{c}$.

7. Данилишин, Б. М. Безпека регіонів України і стратегія іï гарантування [Текст]: монографія: у 2 т. Т. 1. Природно-техногенна (екологічна) безпека / Б. М. Данилишин, А. В. Степаненко, О. М. Ральчук, С. М. Волошин, А. М. Сундук; НАН України, Рада по вивч. продукт. сил України. - К. : Наук. думка, 2008. - 389 с.

8. Дорогунцов, С. І. Державне регулювання техногенно-екологічної безпеки в регіонах України [Текст] / С. I Дорогунцов, А. М. Федорищева // Економіка України. - 2002. № 4. - C. 70-76.

9. Качинський, А. Б. Екологічна безпека України: системний аналіз перспектив покращення [Текст] / А. Б. Качинський. - К.: б. и., 2001. -311 с.

10. Яцик, А. В. Екологічна безпека в Україні [Текст]/ А. В. Яцик. - К.: Генеза, 2001. - 216 с.

11. Buts, Yu. The management by ecological risks and by ecological safety on basis of statistical approach [Text] : 15 medzinárodná vedecká konferencia / Yu. Buts, O. Kraynyuk, 
V. Andronov // Riešenie krízových situácií v špecifickom prostredí, Fakulta špeciálneho inžinierstva ŽU, Žilina, 2010. P. 87-90.

12. Buts, Yu. Theoretical foundations of methodology for studying of emergency situation impacts on geosystems [Text] : Medzinárodná Vedecká Konferencia / Yu. Buts, K. B. Utkina, M. I. Kulik, V. V. Fylenko, E. V. Krainyk, // Bezpečnostné Fórum 2012 // Zbornic vedeckych a odbornych prac. - Univerzita Mateja Bela, Banská Bystrica, 2012. - C. 823-827.

13. Van Zelst, W. H. Prevalence and risk factors of posttraumatic stress disorder in older adults [Text] / W. H. Van Zelst, E. de Beurs, A. T. Beekman, D. J. Deeg, R. van Dyck // Psychotherapy and Psychosomatics. - 2003. - Vol. 72, Issue 6. - P. 333342. doi: $10.1159 / 000073030$

14. Quarantelli, E. L. Ten criteria for evaluating the management of community disasters [Text] / E. L. Quarantelli // Disasters. - 1997. - Vol. 21, Issue 1. - P. 39-56. doi: $10.1111 / 1467-7717.00043$

15. Ruef, A. M. Hispanic ethnicity and risk for combatrelated posttraumatic stress disorder [Text] / A. M. Ruef, B. T. Litz, W. E. Schlenger // Cultural Diversity \& Ethnic Minority Psychology. - 2000. - Vol. 6, Issue 3. - P. 235-251.

doi: $10.1037 / 1099-9809.6 .3 .235$

16. Schulberg, H. C. Disaster, crisis theory and intervention strategies [Text] / H. C. Schulberg // OMEGA - Journal of Death and Dying. - 1974. - Vol. 5, Issue 1. - P. 7-87.

doi: 10.2190/ctrk-j01c-k6ja-ej41

17. Моніторинг та оцінювання екологічних ризиків техногенного походження: аналітична доповідь [Текст] / К.: Вид-во Нац. Інституту стратегічних досліджень, 2012.- 52 с.

\section{References}

1. Nacionalna dopovid pro stan tehnogennoi ta pryrodnoi bezpeki Ukrainy v 2013 roci (2013). Kiev: MNS, 542.

2. Mamontova, O. (Ed.) (2012). Statustuchnuy chorichnuk. Kharkiv: GUS Kharkivskoi obl, 578.

3. Zakon Ukrainy «Pro obektu pidvushenoi nebezpeku» (2001). Vidomosti Verhovnoi Radu (VVR), № 15, 73.

4. Barabashova, N. V. (2002) Ekologichna bezpeka promuslovo rozvunenogo regionu: pravovui aspekt. Donetsk: DonDAU, 227.

5. Begun, V. V. (2004). Bezpeka zhittediaylnosti (zabezpechennay socialnoi, tehnogennoi ta prurodnoi bezpeku): [navch. Posib]. Kiev: Universitet, 328.
6. Danilishin, B. M. (2004). Naukovi osnovu prognozuvannay prurodno-technogennoi (ekologichnoi) bezpeku. Kiev: Leks Dim, 552.

7. Bezpeka regioniv Ukrainu I strategiay ii garantuvannay (2008). Kiev: Nauk. dumka, 1, 392.

8. Doroguntcov, S. I. (2002). Derzhavne reguluvannay technogenno-ekologichnoi bezpeku $\mathrm{v}$ regionach Ukrainu. Ekonomika Ukrainu, 4, 70-76.

9. Kachinskiy, A. B. (2001). Ekologichna bezpeka Ukrainu: sistemnuy analiz perspektiv pokrashennay, Kiev: b.i, 311.

10. Yatsuk, A. V. (2001). Ekologichna bezpeka v Ukraini. Kiev: Geneza, 216.

11. Buts, Yu., Kraynyuk, O., Andronov, V. (2010). The management by ecological risks and by ecological safety on basis of statistical approach. Riešenie krízových situácií v špecifickom prostredí: 15 medzinárodná vedecká konferencia, Fakulta špeciálneho inžinierstva ŽU, Žilina, 87-90.

12. Buts, Yu., Utkina, K. B., Kulik, M. I., Fylenko, V. V., Krainyk, E. V. (2012). Theoretical foundations of methodology for studying of emergency situation impacts on geosystems. Bezpečnostné Fórum 2012: V. Medzinárodná Vedecká Konferencia. Zbornic vedeckych a odbornych prac. Univerzita Mateja Bela, Banská Bystrica, 823-827.

13. Van Zelst, W. H., de Beurs, E., Beekman, A. T., Deeg, D. J., van Dyck, R. (2003). Prevalence and risk factors of posttraumatic stress disorder in older adults. Psychotherapy and Psychosomatics, 72 (6), 333-342. doi: 10.1159/000073030

14. Quarantelli, E. L. (1997) Ten criteria for evaluating the management of community disasters. Disasters, 21 (1), 39-56. doi: 10.1111/1467-7717.00043

15. Ruef, A. M., Litz, B. T., Schlenger, W. E. (2000). Hispanic ethnicity and risk for combat-related posttraumatic stress disorder. Cultural Diversity \& Ethnic Minority Psychology, 6 (3), 235-251. doi: 10.1037/1099-9809.6.3.235

16. Schulberg, H. C. (1974). Disaster, crisis theory and intervention strategies. OMEGA - Journal of Death and Dying, 5 (1), 7-87. doi: 10.2190/ctrk-j0lc-k6ja-ej41

17. Monitogung ta ocinyuvannay ekologichnuh ruzukiv technogennogo pochodzhennay: analituchna dopovid (2012). Kiev: Nac. Instutut strategichnuch doslidzhen, 52.

Рекомендовано до публікації д-р геогр. наук, проф. Некос А. Н. Дата надходження рукопису 17.12.2014

Буц Юрий Васильевич, кандидат географических наук, доцент, кафедра технологии, экологии и безопасности жизнедеятельности, Харьковский национальный экономический университет им. Семена Кузнеца, пр. Ленина, 9а, г. Харьков, Украина, 61166

Крайнюк Елена Владимировна, кандидат технических наук, доцент, кафедра метрологии и безопасности жизнедеятельности, Харьковский национальный автомобильно-дорожный университет, ул. Петровского, 25, г. Харьков, Украина, 61002 